\title{
Percutaneous Coronary Intervention in a Cancer Patient with Dextrocardia and Situs Inversus
}

\author{
Patrick Lahoud* \\ Cardiology Division, Telchiha, Zahle, Lebanon \\ *Corresponding author: Patrick LAHOUD, Cardiology Division, Telchiha, Zahle, Lebanon
}

\begin{abstract}
Although dextrocardia occurs rarely, the incidence of coronary artery disease is similar to the general population [1]. Few cases of coronary angiography and percutaneous coronary intervention $(\mathrm{PCl})$ in patients with dextrocardia have been reported [2]. Because of unfamiliarity with performing catheterization, transradial coronary angiography has seldom been performed in a patient with dextrocardia [1]. To the best of our knowledge, this is the first report of successful coronary angiography and ad hoc coronary stenting in a cancer patient with dextrocardia with situs inversus in Lebanon. We successfully performed right transfemoral coronary angiography in a patient with a right side heart using counter-directional torquing of the catheters and mirror-image angiographic angles.
\end{abstract}

\section{Keywords}

Dextrocardia, Coronary angiography

\section{Introduction}

Dextrocardia occurs rarely, with a frequency estimated at 1:10,000 [2]. There is scant information available to the angiographer faced with performing catheterization in a patient with dextrocardia. Mirror image dextrocardia was first noted in the 1920s and it may be present in about one in 130,000 people. The incidence of coronary artery disease in dextrocardia is similar to the general population [1]. Successful coronary angiography and angioplasty via the femoral artery have previously been performed in patients with dextrocardia [3]. We report successful coronary angiography in a patient with dextrocardia associated with situs inversus totalis. Catheterization in our patient was performed without difficulty using standard techniques.

Case

A 46-year-old white male with known dextrocardia presented with severe substernal chest pain. He had been managed for hypertension and major (submandibular) advanced salivary gland cancer (adenocarcinoma) with distant metastasis (Stage IV) treated with definitive radiotherapy. He had no family history of coronary artery disease. The patient's social history revealed tobacco consumption, without alcohol or illicit drug use.

In the emergency department, his heart rate was 75 beats per minute, and his blood pressure was 149/90 $\mathrm{mmHg}$. he was breathing 16 times per minute with a pulse oximetric saturation of $94 \%$ on room air. Neck examination revealed no jugular venous distension and normal carotid upstrokes without bruits with neck lumps. Auscultation of the lungs revealed good bilateral air entry. The point of maximum impulse was located in the fourth intercostal space just left of the right midclavicular line. Cardiac auscultation demonstrated a regular rate and rhythm with a normal first and second heart sound. No murmurs, rubs, or gallops were heard. No clubbing, cyanosis, or edema was noted (Figure 1).

Chest X-ray was remarkable for dextrocardia and right-sided stomach bubble. Electrocardiogram, with the properly reversed leads for dextrocardia (Figure 2 ), showed ST elevation in anterior leads with resolution of ST elevation and clinical improvement 10 minutes after medical Treatment (ticagrelol $90 \mathrm{mg} 2$ tablets aspegic $250 \mathrm{mg}$ intravenously and heparine $5000 \mathrm{UI}$ intravenously) and persistence of early repolarisation pattern. Two-dimensional echocardiogram showed a left-sided liver and dextrocardia without other abnormalities. The patient's initial troponin $\mathrm{T}$ and creatine kinase-MB levels were $29.34 \mathrm{pg} / \mathrm{mL}$ (negative) and $1.3 \mathrm{ng} / \mathrm{mL}$, respectively. Troponin and

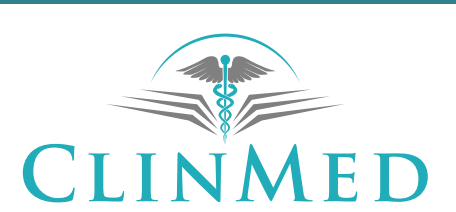

INTERNATIONAL LIBRARY

Citation: Lahoud P (2019) Percutaneous Coronary Intervention in a Cancer Patient with Dextrocardia and Situs Inversus. Clin Med Rev Case Rep 6:290. doi.org/10.23937/2378-3656/1410290

Accepted: October 23, 2019: Published: October 25, 2019

Copyright: (C) 2019 Lahoud P, et al. This is an open-access article distributed under the terms of the Creative Commons Attribution License, which permits unrestricted use, distribution, and reproduction in any medium, provided the original author and source are credited. 


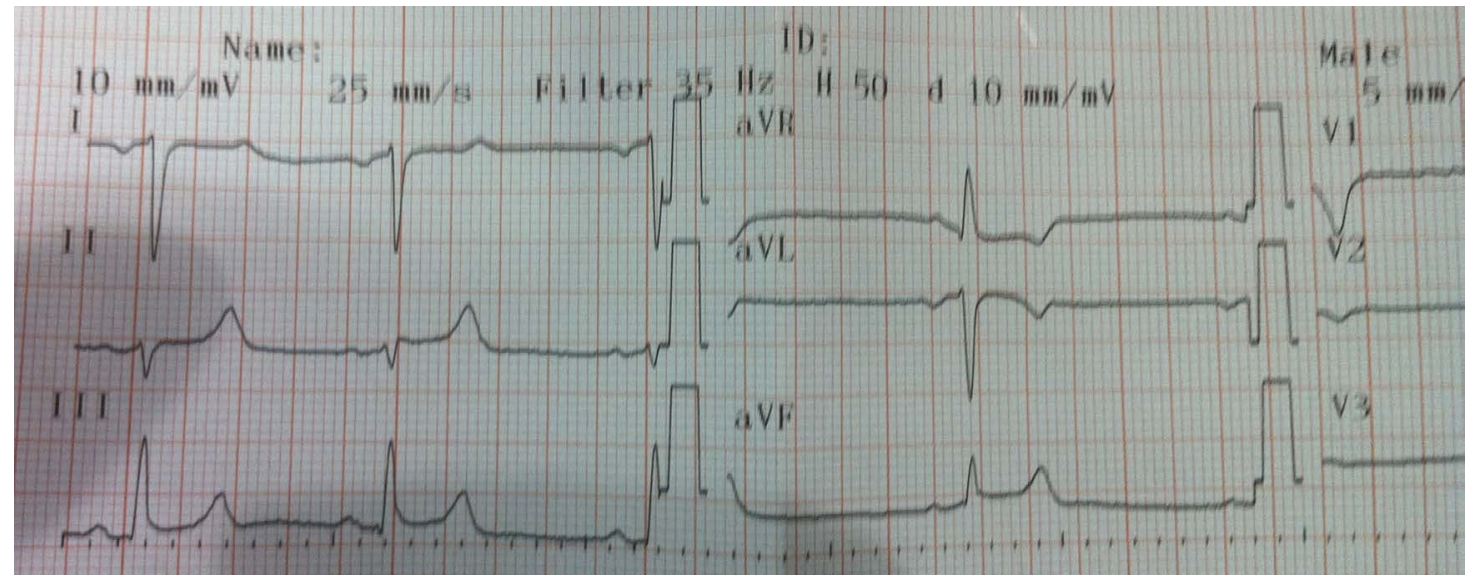

Figure 1: A resting standard electrocardiogram of a 46-year-old Lebanese man. He had inversion of $P$ waves in leads I and aVL, dominant $S$ wave in lead I and inverted $T$ wave in lead aVL.

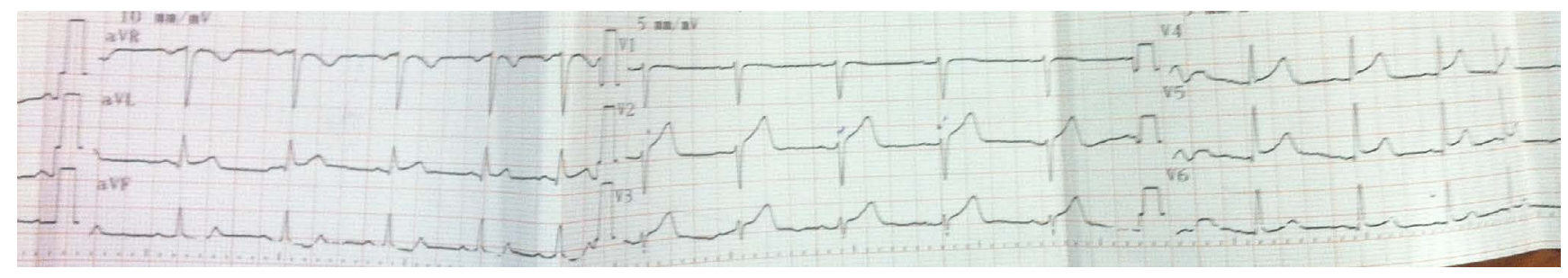

Figure 2: A resting standard electrocardiogram of a 46-year-old Lebanese man with the electrocardiogram electrodes reversed.

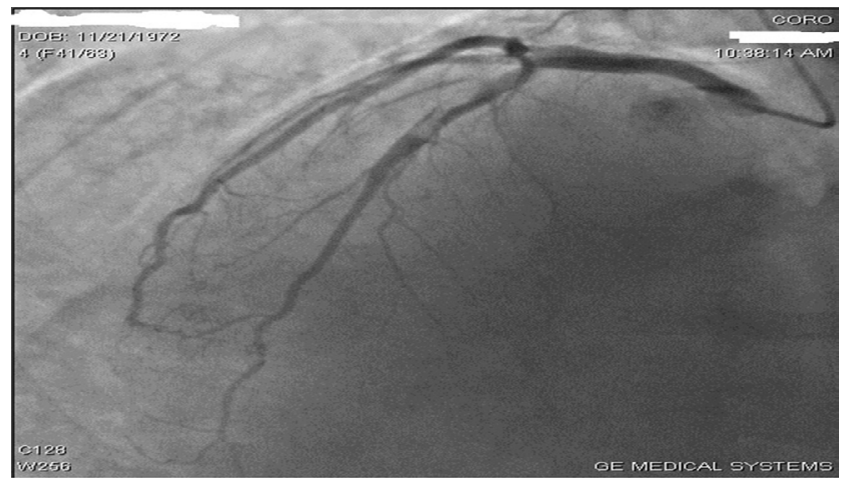

Figure 3: LAD presented a mid $95 \%$ lesion with dissection and thrombus at this level.

creatine kinase-MB levels after few hours were 296.1 $\mathrm{pg} / \mathrm{ml}$ (positive) and $7.57 \mathrm{ng} / \mathrm{ml}$. Cardiac catheterization was performed from the right femoral artery. Selective coronary angiograms were obtained using counter-directional torquing of Judkins Left- 4 and Judkins Right-4 diagnostic catheters and mirror-image angiographic angles. Left main coronary artery was normal. The left anterior descending artery presented a mid $95 \%$ lesion with dissection and thrombus at this level (Figure 3). The left circumflex artery was infiltrated with $60 \%$ mid lesion. The dominant right coronary artery was infiltrated. Left anterior descending artery lesion was successfully treated with direct stenting with a xience Xpedition $3.0 \times 38-\mathrm{mm}$

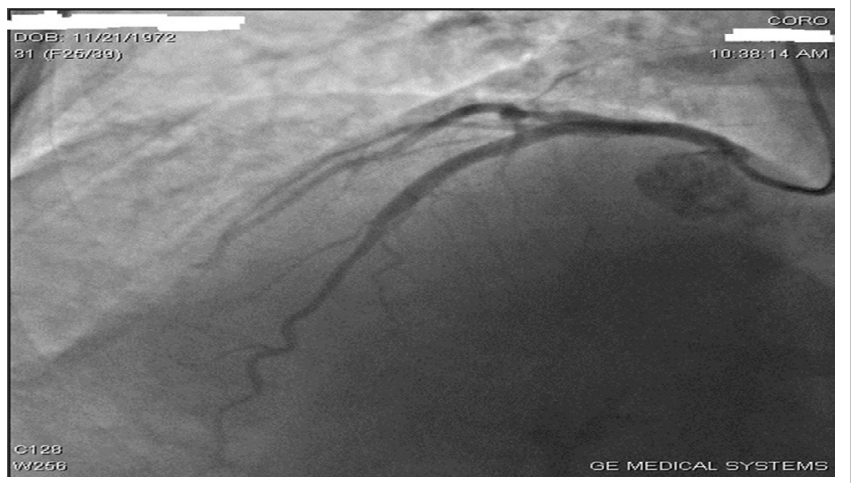

Figure 4: LAD lesion was successfully treated with direct stenting.

stent through a Judkins Left-3.5 guide catheter (Figure 4).

\section{Discussion}

The incidence of coronary artery disease in dextrocardia is presumably similar to the general population [1]. Since the first diagnostic cardiac catheterization in a patient with dextrocardia in 1973, few have reported transfemoral catheterization procedures [3].

There have been several reported approaches to classify cardiac malposition. The simplest method is to describe cardiac position, visceroatrial situs, and ventriculoarterial position.

Dextrocardia is one of the cardiac anomalies that 
presents itself with unusual and specific electrocardiographic features which include inversion of $P$ waves in leads $I$ and $\mathrm{aVL}$, dominant $\mathrm{S}$ waves in leads $\mathrm{I}$ and $\mathrm{V} 1$ to $V 6$, reversed $R$ wave progression in chest leads, low voltage QRS axis in V4 to V6, extreme QRS axis, flattened T waves in V4 to V6 and aVR and inverted T waves in lead I and aVL.

Dextrocardia with situs inversus may occur with other features in the respiratory tract. Kartagener syndrome occurs in approximately $25 \%$ of individuals with mirror image dextrocardia. This disorder is characterized by dextrocardia with situs inversus, sinusitis and bronchiectasis; it is associated with primary ciliary dyskinesia. The genetic basis for dextrocardia with situs inversus is not well understood. Familial tendency to dextrocardia was described by Ibrahim in 2013 in Nigeria [4]. The type of dextrocardia associated with respiratory abnormalities was said to be autosomal recessive; however, Soltan and Li [4] described the cardiac anomaly in a kindred group in which four males were affected which suggested an X-linked recessive inheritance. Both autosomal recessive and $X$-linked variants have been described [4]. Because of the genetic nature of this cardiac anomaly, many unidentified cases are likely to exist among the general population which may pose diagnostic and management dilemmas to physicians because of unusual presentations at unpredictable moments [4]. So, screening of an apparently healthy adult population with ECG may resolve some of these medical enigmas and other asymptomatic cardiovascular disorders.

The most important modifications in performing coronary angiogram in patients with dextrocardia are opposite-direction catheter rotations and mirror-image angiographic angles, i.e., anticlockwise rotation in the ascending aorta for the right coronary artery and reversing the required right anterior oblique/left anterior oblique angles but keeping the cranial/caudal tilts the same [3]. Other angiographers used a double-inversion technique, which normalizes all angiographic pictures to the standard conventional pictures as seen in a normally located heart [1]. In our case, we performed coronary angiography with a transfemoral approach, with counter-directional torquing of the catheter, as well as right-left mirror-image inversion angiographic views. We did not do further image reversal to employ traditional views.

There has been no consensus in selecting imaging catheters. Moreyra, et al. reported that regular coronary catheters (Judkins) are difficult to use because of the reversed position of the coronary ostia, and recommended nontraditional catheters with wider curves and longer tips. Otherwise, both the left and right coronaries were successfully cannulated with Judkins catheters in other reports [3]. In our case, left coronaries were easily engaged with a Judkins Left-4 catheter and right coronary artery with Judkins Right-4 catheter. The use of opposite-directional torquing of these catheters in mirror-image angio- graphic angles allowed uncomplicated right transfemoral angiography in a patient with right sided heart, dextrocardia.

The literature on diagnosis and treatment of atherosclerosis in patients with dextrocardia is scant. The prevalence of coronary artery disease is thought to be no different in patients with or without dextrocardia, over 80 patients per year with dextrocardia may undergo cardiac catheterization [2]. Coronary angiography was first reported in dextrocardia in 1974 in a patient who underwent left ventricular aneurysmectomy [2]. In 1991, Blankenship [2] summarized a total of 10 cases with dextrocardia and coronary heart disease, on whom catheterizations were performed without difficulty by using Judkins technique in 5 cases, and Sones technique in four, and with only 1 case requiring additional catheters. Coronary artery bypass surgery in a patient with dextrocardia was described in 1982, [2] and coronary grafting with a right internal mammary artery was reported in 1988. As for $\mathrm{PCl}$ techniques, 2 patients undergoing coronary angioplasty were reported by Moreyra in 1987 and Gaglani in 1989. Lewis reported directional coronary atherectomy in 1993, Waster reported coronary angioplasty in a single coronary artery in 1994 and Kay reported rotational atherectomy in 2002 [5] for patients with dextrocardia and situs inversus. In dextrocardia, positions of the coronary artery ostia relative to the sinuses and to the aortic arch are a mirror-image of the normal orientation. Since coronary catheters are not "left-" or "right-handed", they assume a mirror-image position in the mirror-image anatomy. Thus, they maintain their standard relationships to the coronary ostia. Catheters can be passed using standard technique, except that catheters are rotated in the opposite site direction (e.g., counterclockwise to seat a Judkins right catheter) [6].

It should be noted that for both the right and the left coronary arteries in biplane angiography, the LAO and RAO angulations are essentially reversed from the normal biplane angulations. Of course, appropriate mirror-image view with somewhat modified angulations to achieve the better visualization of coronary arteries is mandatory. In our experience, we utilized the mirror-image views with subtle modification of angle and opposite-direction catheter rotation. The selective left coronary angiograms were obtained in the RAO cranial, postero-anterior (PA) cranial and LAO caudal views with some appropriate angulations, respectively. The selective right coronary angiograms were obtained in the RAO 60, PA cranial and LAO 30 views. As for the $\mathrm{PCl}$ techniques, they were similar to the diagnostic procedures. We report that the standard angiographic techniques described above using opposite-direction catheter rotations and mirror-image views are useful for both angiography and angioplasty procedures in dextrocardic patients. Furthermore, varieties of $\mathrm{PCl}$ (balloon angioplasty, stenting, 
etc.) are likewise applicable to patients with dextrocardia.

Interpretation of angiographic images may be difficult and unfamiliar. Image appearance, therefore, can be improved by horizontally reversing the image and/or inverting the position (i.e., right-left substitution) of the $x$-ray image intensifier during the procedure [7]. In this case, normal rotational movements and image acquisition techniques were successfully employed.

This case is the first reported instance of acute coronary syndrome occurring in a cancer patient with dextrocardia with situs inversus who was successfully treated with coronary stent implantation.

In summary, our report demonstrates the feasibility of angiography and angioplasty in the patient with dextrocardia.

\section{Conclusion}

In a patient with previously unknown cardiac status (dextrocardia or cardiac diseases), the initial presenting symptoms may be confusion due to the fact that the heart is in the right side of the chest. This may present a confusing status for treating physician during diagnosis or investigations. Therefore, in urgent situations with right sided symptoms, the cardiac conditions still need to be considered for timely diagnosis.

Few angiographers will see more than one patient with dextrocardia and situs inversus during their career. We offer this information so that the angiographer faced for the first time with such a patient can be reassured that standard techniques, with the exceptions of opposite direction catheter rotation and mirror-image angiographic angles will usually allow uncomplicated coronary angiography and angioplasty.

\section{References}

1. Gil-Su Jang, Hyun-Sook Kim, Won-Yong Lee, Kun II Kim, Ju-Seok Kim, et al. (2010) Left transradial coronary angiography in a patient with dextrocardia. Korean Circ J 40: 601-603.

2. Blankenship JC, Ramiers JA (1991) Coronary arteriography in patients with dextrocardia. Cathet Cardiovasc Diagn 23: $103-106$.

3. Jauhar R, Gianos E, Kashifuddin B, Roethel M, Kaplan BM (2005) Primary angioplasty in a patient with dextrocardia. J Interv Cardiol 18: 127-130.

4. Oluwadare O, Abiodun A, Rufus A, Olumide A, Adedayo I, et al. (2015) The role of electrocardiogram in the diagnosis of dextrocardia with mirror image atrial arrangement and ventricular position in a young adult Nigerian in lle-Ife: A case report. J Med Case Rep 9: 222.

5. Kay J, Kwok OH, Chow WH (2002) Successful rotational atherectomy and stenting in a situs inversus patient. $J$ Invas Cardiol 14: 682-685.

6. Mehmet Çilingiroglu, Mohammad-Abdul Waheed, Nuri Akkufl (2008) Coronary angiography in a patient with situs inversus and dextrocardia Situs inversuslu, ve dekstrokardili bir hastada koroner anjiyografi. Anadolu Kardiyol Derg 8: 455-460.

7. Goel PK (2005) Double-inversion technique for coronary angiography viewing in dextrocardia. Catheter Cardiovasc Interv 66: 281-285. 